This item was submitted to Loughborough's Research Repository by the author.

Items in Figshare are protected by copyright, with all rights reserved, unless otherwise indicated.

\title{
Environmental factors affecting Hong Kong banking : a post-Asian financial crisis efficiency analysis
}

PLEASE CITE THE PUBLISHED VERSION

PUBLISHER

(c) Loughborough University

VERSION

VoR (Version of Record)

LICENCE

CC BY-NC-ND 4.0

\section{REPOSITORY RECORD}

Hall, Maximilian J.B., Karligash Kenjegalieva, and Richard Simper. 2019. "Environmental Factors Affecting Hong Kong Banking : A Post-asian Financial Crisis Efficiency Analysis”. figshare. https://hdl.handle.net/2134/4179. 
This item was submitted to Loughborough's Institutional Repository (https://dspace.lboro.ac.uk/) by the author and is made available under the following Creative Commons Licence conditions.

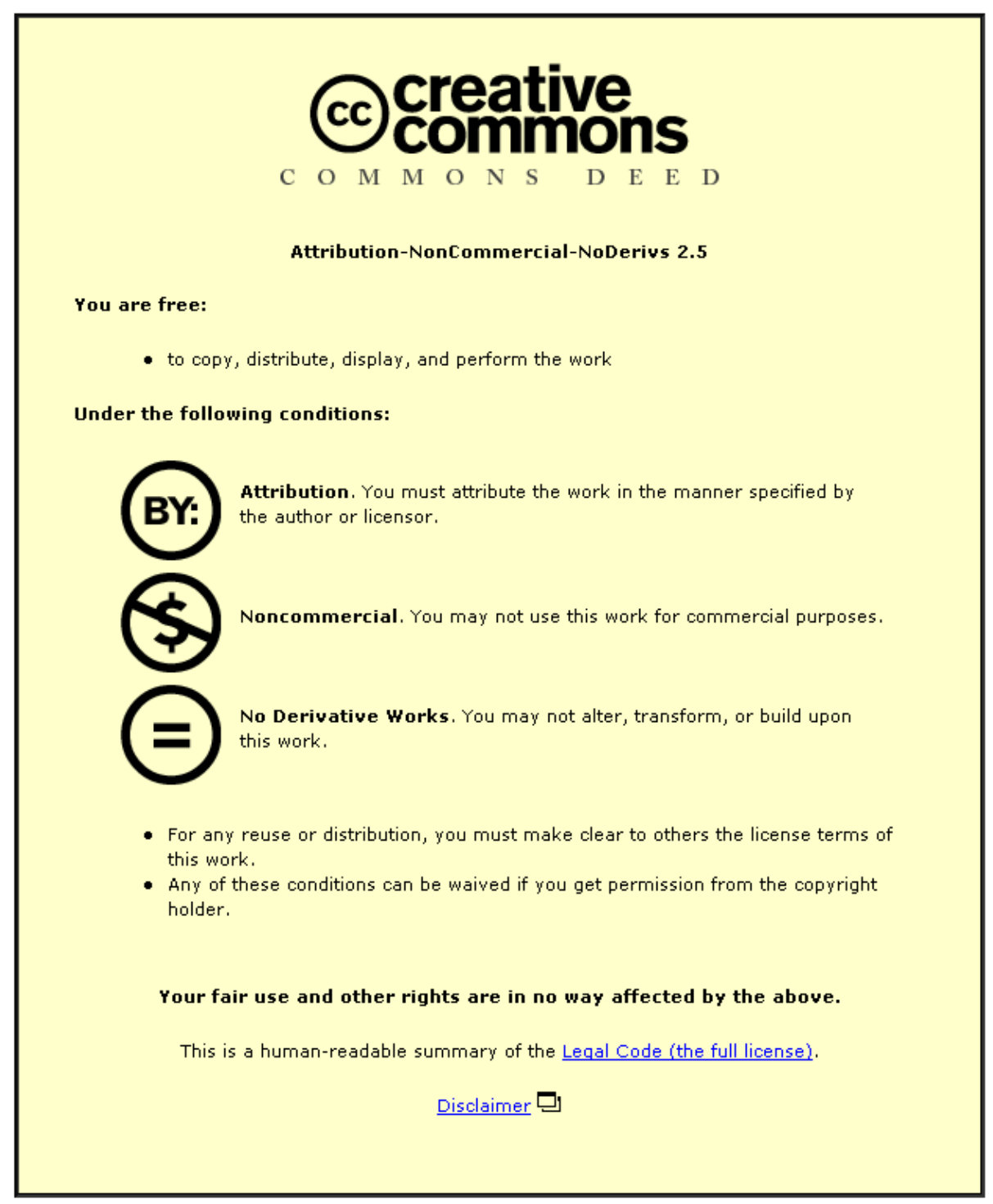

For the full text of this licence, please go to: http://creativecommons.org/licenses/by-nc-nd/2.5/ 
ISSN 1750-4171

\title{
DEPARTMENT OF ECONOMICS
}

\author{
DISCUSSION PAPER SERIES
}

\section{Environmental Factors Affecting Hong Kong Banking: A Post-Asian Financial Crisis Efficiency Analysis}

\author{
Maximilian J. B. Hall \\ Karligash Kenjegalieva \\ Richard Simper
}

WP 2008 - 01

Dept Economics 


\title{
Environmental Factors Affecting Hong Kong Banking: A Post-Asian Financial Crisis Efficiency Analysis
}

\author{
Maximilian J. B. Hall ${ }^{\dagger}$, Karligash A. Kenjegalieva and Richard Simper ${ }^{\dagger *}$ \\ Department of Economics, Loughborough University, \\ Ashby Road, Loughborough, United Kingdom, LE11 3TU.
}

\begin{abstract}
Within the banking efficiency analysis literature there is a dearth of studies which have considered how banks have 'survived' the Asian financial crisis of the late 1990s. Considering the profound changes that have occurred in the region's financial systems since then, such an analysis is both timely and warranted. This paper examines the evolution of Hong Kong's banking industry's efficiency and its macroeconomic determinants through the prism of two alternative approaches to banking production based on the intermediation and services-producing goals of bank management over the post-crisis period. Within this research strategy we employ Tone's (2001) Slacks-Based Model (SBM) combining it with recent bootstrapping techniques, namely the non-parametric truncated regression analysis suggested by Simar and Wilson (2007) and Simar and Zelenyuk's (2007) group-wise heterogeneous sub-sampling approach. We find that there was a significant negative effect on Hong Kong bank efficiency in 2001, which we ascribe to the fallout from the terrorist attacks in America in $9 / 11$ and to the completion of deposit rate deregulation that year. However, post 2001 most banks have reported a steady increase in efficiency leading to a better 'intermediation' and 'production' of activities than in the base year of 2000, with the SARS epidemic having surprisingly little effect in 2003. It was also interesting to find that the smaller banks were more efficient than the larger banks, but the latter were also able to enjoy economies of scale. This size factor was linked to the exportability of financial services. Other environmental factors found to be significantly impacting on bank efficiency were private consumption and housing rent.
\end{abstract}

$\dagger$ The financial support of the Hong Kong Institute for Monetary Research, where the co-authors were Research Fellows, is gratefully acknowledged.

* Corresponding author. Tel +44 (0)1509 222701; fax: +44 (0)1509 223910.

E-mail address: r.simper@lboro.ac.uk 
JEL Classification: C23; C52: G21

Keywords: Finance and Banking; Productivity; Efficiency

\section{Introduction}

The Asian Financial Crisis (AFC), which erupted in Thailand during the Summer of 1997 and went on to cause such economic and financial devastation in the region in ensuing years, has been well documented (see, for example, Goldstein (1998) Hunter, Kaufman and Krueger (1999), and Jao (2001)). Hong Kong was one of just a few countries in the region to escape relatively unscathed, successfully avoiding a banking crisis although, of course, some damage was inflicted on the banks. The damage wrought by the AFC on the banks' balance sheets was limited, however, by sound regulation introduced in the aftermath of the 1983-86 crisis and strong capitalisation. Supervisory reform in the wake of the AFC was thus largely unnecessary in Hong Kong, although the process of financial liberalisation continued.

Previous studies that have investigated those countries that were involved in the AFC have primarily considered how banking systems operated throughout the turbulent period. For example, Shen (2005) employed a smooth transition parametric model to analyse the changes to banks' balance sheets (traditional loans to off balance sheet items) during the AFC of Taiwanese banks during 1996-2001. It was found that during this period the traditional banks experienced decreasing returns to scale in loan markets, and banks which followed the universal-style banking system experienced increasing returns to scale in the off balance sheet markets. In Malaysia, Krishnasamy et al (2003), showed that the banking system consolidated from 86 banks in 1997 to 45 in 2002 as the AFC hit profits. They found, utilising non-parametric Malmquist indices, that the top ten banks in Malaysia faced a reduction in technical efficiency of $4.2 \%$ and in scale efficiency of $5.1 \%$ over the period 2000-2001. Finally, Drake et al. (2006) showed that x-efficiency scores utilising the nonparametric Slacks-Based Measure decreased by over half for some asset-sized groups of Hong Kong banks after the 1997 AFC (for example, for banks with assets between US\$1000m and US\$4999m, mean $x$-efficiencies decreased from 62\% (1997) to 39\% (1998)). 
However, unlike the previous studies, Drake et al. (2006) differed in their analysis by arguing that when considering bank systems that experience a downturn in efficiency due to market conditions, external factors affecting the banking system should be taken into account empirically. This is especially important when a banking system that is to be modelled has numerous different sectors of the banking industry included for comparison. That is, certain environmental/macroeconomic factors could cause x-efficiencies to fall by more for a certain bank group than for a bank group not dependent upon that former bank group's primary market; for example, banks involved in the mortgage market and commercial investment markets. Given these difficulties, when modelling banking systems not only should intergroup bank differences be taken into account but also any changes in environmental/macroeconomic factors that could distort efficiency results, thus possibly biasing financial policy within the country considered.

With respect to the latter problem in modelling bank systems, it has long been recognised that environmental factors can have a significant impact on relative efficiency scores. For example, Fried et al. (1999) argue that production efficiencies can be decomposed into three parts: management efficiencies or X-efficiencies; the impact of environmental factors; and the impact of 'good or bad luck'. The first is endogenous, whereas the latter two factors are exogenous to the banks' management; the idea is therefore to disentangle the latter two effects in an analysis of Hong Kong banks. Hence, in this paper, using Monte Carlo methods, we remove the bias associated with the 'good/bad luck' as a random error using a new technique proposed by Simar and Zelenyuk (2007). This also allows us to further determine confidence intervals for the banks using a group-wise heterogeneous sub-sampling approach. Having taken into account the 'random error' problem, the paper then considers the effects of macroeconomic and environmental factors on the efficiency scores, rather than directly incorporating them into the DEA program (as done, for example, by Drake et al. (2006) and Lozano-Vivas et al. (2002)).

The paper is organised as follows. In the next Section we discuss the changing nature of Hong Kong banking since the AFC. In Section 3 we present our non-parametric methodology and boot-strapping approach to examining Hong Kong Banking, and also the data utilised in both the 'intermediation' and 'production' modelling methodologies. Our results are presented in Section 4 and we conclude in Section 5. 


\section{Hong Kong, the Asian financial crisis and more recent developments}

Given the remarkable degree of resilience to the AFC shown by Hong Kong's banking sector, it is not surprising that clarion calls for supervisory reform were notable for their absence. This would suggest that the reforms implemented in 1986 embracing, inter alia (see Hall, 1985, for further details), a tightening up of licensing procedures (e.g. involving tougher vetting of all prospective owners, directors and managers), the imposition of stricter limits on loan exposures to group companies and directors, and the introduction of a 5 per cent minimum capital adequacy ratio (which could be raised to 8 per cent for banks and 10 per cent for deposit-taking companies) - replaced in 1990 with a Basel I compliant risk-based minimum ratio of 8 per cent - had done their job in restoring stability to the sector.

Financial liberalisation, however, continued apace. Following the earlier "structural" reforms, which culminated in the creation of a three-tier banking system in 1990 (whereby "licensed banks" are distinguished from "restricted license banks" and "deposit-taking companies" - see Jao, 2003, for further details) interest rate controls have been gradually lifted and restrictions on foreign banks relaxed. The former involved the removal of the interest rate cap on retail deposits of more than one month on 1 October 1994, followed by the removal of interest rate caps on retail deposits of more than seven days and exactly seven days on 3 January 1995 and 1 November 1995 respectively. The cap on time deposits of less than seven days duly disappeared on 3 July 2000, followed by the complete deregulation of savings and current account deposit rates on 3 July 2001. As for the restrictions imposed on foreign banks, the "one-building" restriction was relaxed to a "three-building" restriction on 17 September 1999 and then, in November 2001, this latter restriction was abolished. Market entry criteria for foreign banks were also relaxed in May 2002. Such, then, was the

nature of the more liberal regulatory environment within which Hong Kong's banks operated post-1999, the timeframe of this paper's analysis. Moreover, the banks have been able to engage in renminbi- dominated retail banking operations since January 2004. 
As far as the likely impact of these regulatory developments on bank fortunes is concerned, the main focus of attention should probably be on the interest rate liberalisation programme and relaxed market entry criteria. Assuming that, in the past, the profitability of banks operating in Hong Kong was boosted, via monopsonistic rents, by the application of such controls - especially the caps imposed on deposit rates and the restrictions imposed on new bank entry and branching - it is to be expected that reforms adopted in these areas will have served to dampen the banks' profits. Indeed, the Hong Kong Monetary Authority noted as early as 2002( HKMA, 2002) that the increased competition had resulted in a reduction in bank lending spreads, particularly in the mortgage loan market, and downward pressure on net interest margins, particularly for small banks. Some banks, however, and especially the larger ones, managed to offset such adverse effects on profitability by boosting non-interest (i.e. fee and commission-based) income and reducing operating costs by, for example, encouraging customers with low and volatile balances to use less-costly delivery channels, such as the Internet. Account charges are now also the norm. As far as the smaller banks are concerned, the introduction of deposit insurance in 2006 should have acted to increase the relative attraction of small licensed banks by reducing the competitive advantage enjoyed by "Too-Big-Too-Fail" banks; whilst many also view deposit deregulation as an opportunity allowing them to compete more effectively for deposits with large listed banks. Finally, the opening-up of some renminbi-denominated business to Hong Kong's licensed banks in January 2004 served to provide these banks with some additional revenue, despite the PRC's stringent capital controls. Moreover, the Chinese government's subsequent decision to relax exchange controls by allowing Mainland banks to issue renminbi-denominated credit cards which can be used at ATMs in Hong Kong should further boost fee income for the latter region's banks.

\section{Modelling Theory and Data}

\subsection{Estimation of efficiency}

Data Envelopment Analysis (DEA) originated from Farrell's (1957) seminal work and was later elaborated on by Charnes et al. (1978), Banker et al. (1984) and Färe et al. (1985). 
The objective of DEA is to construct a relative efficiency frontier through the envelopment of the Decision Making Units (DMUs) where the 'best practice' DMUs form the frontier. In this study, we utilize a DEA model which takes into account input and output slacks, the socalled Slacks-Based Model (SBM), which was introduced by Tone (2001) and ensures that, in non-parametric modelling, the slacks are taken into account in the efficiency scores. For, as Fried et al. (1999) argued, in the 'standard' DEA models based on the Banker et al. (1984) specification "the solution to the DEA problem yields the Farrell radial measure of technical efficiency plus additional non-radial input savings (slacks) and output expansions (surpluses). In typical DEA studies, slacks and surpluses are neglected at worst and relegated to the background at best" (page 250). Indeed, in the analysis of non-public sector DMUs, for which DEA was originally proposed by Farrell, the idea of slacks was not a problem unlike it is when DEA is employed to measure cost efficiencies in a 'competitive market' setting. That is, in a 'competitive market' setting, output and input slacks are essentially associated with the violation of 'neo-classical' assumptions. For example, in an inputoriented approach, the input slacks would be associated with the assumption of strong or free disposability of inputs which permits zero marginal productivity of inputs and hence extensions of the relevant isoquants to form horizontal or vertical facets. In such cases, units which are deemed to be radial or Farrell efficient (in the sense that no further proportional reduction in inputs is possible without sacrificing output), may nevertheless be able to implement further reductions in some inputs. Such additional potential input reductions are typically referred to as non-radial input slacks, in contrast to the radial slacks associated with DEA or Farrell inefficiency i.e., radial deviations from the efficient frontier.

In addition, most DEA models do not deal directly with or allow for negative data in the program variable set. For example, if input variable(s) are found to be negative, then a large arbitrary number is usually added to make that variable(s) positive so that the standard output-oriented Banker et al. (1984) program can then be utilised. The same problem occurs with negative output variable(s), and in this case the input-oriented Banker et al. (1984) model has to be used. Both of these situations occur due to the restricted translation invariance of the Banker et al. (1984) model (see Pastor (1996)). However, a problem arises if both input and output variables include negative values, because in this case the Banker et 
al. (1984) - based programs cannot be utilised; see Silva-Portela et al. (2004). ${ }^{1}$ Further, as argued above, there are also limitations in the Banker et al. (1984) program due to slacks, which also need to be taken into account in the efficiency estimation of profit-orientated firms. Hence, we believe that it is important that both these potential problems are overcome. In this paper, this is done by utilising a Modified Slacks-Based Measure (MSBM) model suggested by Sharp et al. (2006), who combined the ideas of Tone (2001) and Silva Portela et al. (2004). An exposition of the MSBM approach follows.

In modelling we assume there are $n$ DMUs operating in the banking industry which convert inputs $X(m \times n)$ into outputs $\mathrm{Y}(s \times n)$ using common technology $T$ which can be characterised by the technology set $\hat{T}$ estimated using DEA:

$$
\hat{T}=\left\{(x, y) \in \mid y_{o} \leq Y \lambda, x_{o} \geq X \lambda, \sum \lambda=1, \lambda \geq 0\right\}
$$

where $x_{o}$ and $y_{o}$ represent observed inputs and outputs of a particular DMU and $\lambda$ is the intensity variable. $\hat{T}$ is a consistent estimator of the unobserved true technology set under variable returns to scale. This means that, given our aim of analyzing the impact of environmental factors on the SBM efficiency scores, the assumptions outlined in Simar and Wilson (2007) hold, hence allowing for the provision of consistent estimators of the parameters in a fully specified, semi-parametric Data Generating Process (DGP).

Given these conditions, the individual input-oriented efficiency for each DMU is computed relative to the estimated frontier by solving the following MSBM linear programming problem:

$$
\begin{array}{ll}
\min & \hat{\rho}(x, y \mid T(x))=1-\frac{1}{m} \sum_{k=1}^{m} s_{k}^{-} / P_{k o}^{-} \\
\text {subject to } & x_{o}=X \lambda+s^{-},
\end{array}
$$

\footnotetext{
1 Indeed, it is not uncommon for many types of industry to experience negative inputs and outputs in the normal process of production modelling. For example, many banks have entered the lucrative off-balance-sheet market (an output) but in some years trading losses have exceeded gains and hence given rise to a negative output. Unlike other DEA models this could not be modelled as a 'bad' output as it may only involve a small section of the sample banks. In relation to negative inputs, in banking this is common, and in this study we examine the use of Loan Loss Provisions as an input instead of a 'bad' output.
} 


$$
\begin{aligned}
& y_{o}=Y \lambda-s^{+}, \\
& \sum \lambda=1,
\end{aligned}
$$

and

$$
\lambda \geq 0, \quad s^{-} \geq 0, \quad s^{+} \geq 0,
$$

where $s^{-}$is output shortfall, $s^{+}$is input excess, and an optimal solution of program (2) is given by $\left(\hat{\tau}, \hat{\lambda}, \hat{s}^{-}, \hat{s}^{+}\right) . P_{k o}^{-}$is a range of possible improvements for inputs of unit $o$ and is given by $P_{k o}^{-}=x_{k o}-\min _{i}\left(x_{k i}\right)$.

However, the efficiencies calculated utilizing program (2) are biased downwards in relation to the true slacks-based technical efficiencies, $\rho_{i}(x, y \mid P(x))$. To overcome this problem as well as to examine the groups of banks by type and time period, we utilize the group-wise heterogeneous sub-sampling approach suggested by Simar and Zelenyuk $(2007)^{2}$. First, we compute the efficiency score $\hat{\rho}_{i}(x, y \mid P(x))$ for each bank in the sample using program (2). Then, we aggregate the estimates of individual efficiencies into the L-subgroup estimated aggregates by type of bank and also by time period. In our analysis, for aggregation we use the price independent aggregation method suggested by Färe and Zelenyuk (2003) shown below:

$$
\overline{\hat{\rho}}^{l}=\sum_{i=1}^{n l} \hat{\rho}^{l, i} \cdot S^{l, i}, \quad \text { where } S^{l, i}=\frac{1}{D} \sum_{d=1}^{D} \frac{x_{d}^{l, i}}{\sum_{i=1}^{n l} y_{d}^{l, i} \cdot S^{l}}, i=1, \ldots, n_{l} ;
$$

and

$$
\overline{\hat{\rho}}=\sum_{l=1}^{L} \overline{\hat{\rho}}^{l} \cdot S^{l}, \quad \text { where } S^{l}=\frac{1}{D} \sum_{d=1}^{D} \frac{\sum_{i=1}^{n l} x_{d}^{l, i}}{\sum_{l=1}^{L} \sum_{i=1}^{n l} y_{d}^{l, i}}, i=1, \ldots, n_{l}, l=1, \ldots, L
$$

\footnotetext{
${ }^{2}$ Matlab codes for the group-wise heterogeneous sub-sampling procedure for the traditional DEA models coded by Simar and Zelenyuk (2007) were obtained from the Journal of Applied Econometrics web-site.
} 
where, $\overline{\hat{\rho}}^{l}$ is the aggregate efficiency of sub-group $l, S^{l, i}$ is a price independent weight of firm $i$ which belongs to sub-group $l, \overline{\hat{\rho}}$ is the aggregate efficiency of the industry, and $S^{l}$ is a price independent weight of sub-group $l$.

Next, in Step 3, we obtain the bootstrap sequence $\Xi_{s l, b}^{*}=\left\{\left(x_{b}^{*_{i}}, y_{b}^{*_{i}}\right): i=1, \ldots, s_{l}\right\}$ by sub-sampling and replacing data independently for each sub-group $l$ of the original sample $\Xi_{n l}^{*}=\left\{\left(x^{i}, y^{i}\right): i=1, \ldots, n_{l}\right\}$ for each bootstrap iteration $b=1, \ldots, B$, where $s_{l} \equiv\left(n_{l}\right)^{k}$, and where $k<1, l=1, \ldots, L$. The Monte-Carlo evidence presented in Simar and Zelenyuk (2007) indicates that values of $\mathrm{k}$ in the range 0.5 and 0.7 will offer the most precise results in the simulated examples. Hence, in our analysis, we use $k=0.65$ for each sub-group.

Step 4 involves computing the bootstrap estimates of slacks-based efficiency $\hat{\rho}_{b}^{* l, i}$ for banks $i=1, \ldots ., s_{l}<n_{l}$ for all groups $l=1, \ldots, L$ using (2) but with respect to the bootstrapped sample $\Xi_{n, b}^{*}$ obtained in Step 3, i.e.,

$$
\begin{array}{ll}
\min : & \hat{\rho}_{b}^{*,, i}(x, y \mid T(x))=1-\frac{1}{m} \sum_{k=1}^{m} s_{b k}^{*-} / x_{k o} \\
\text { subject to } & x_{o}=X_{b}^{*} \lambda+s_{b}^{*-}, \\
& y_{o}=Y_{b}^{*} \lambda-s_{b}^{*+}, \\
& \sum \lambda=1, \\
& \lambda \geq 0, \quad s_{b}^{*-} \geq 0, \quad s_{b}^{*+} \geq 0 .
\end{array}
$$

Finally, in Step 5, the bootstrapped estimates of the aggregated efficiency are computed using the following equations:

$$
\overline{\hat{\rho}}_{b}^{* l}=\sum_{i=1}^{n l} \hat{\rho}_{b}^{* l, i} \cdot S_{b}^{* l, i} \text {, where } S_{b}^{* l, i}=\frac{1}{D} \sum_{d=1}^{D} \frac{x_{b, d}^{* l, i}}{\sum_{i=1}^{s l} y_{b, d}^{*,,} \cdot S_{b}^{* l}}, i=1, \ldots, s_{l}<n_{l} ;
$$

and 


$$
\overline{\hat{\rho}}_{b}^{*}=\sum_{l=1}^{L} \overline{\hat{\rho}}_{b}^{* l} \cdot S_{b}^{* l}, \quad \text { where } S_{b}^{* l}=\frac{1}{D} \sum_{d=1}^{D} \frac{\sum_{i=1}^{n l} x_{b, d}^{* l, i}}{\sum_{l=1}^{L} \sum_{i=1}^{s l} y_{b, d}^{* l, i}}, i=1, \ldots, s_{l}<n_{l}, l=1, \ldots, L .
$$

Repeating the Steps $3-5 B$ times provides us with $B$ bootstrap-estimates of estimated aggregate efficiencies for each sub-group by type of bank and time period. These estimates allow us to obtain confidence intervals, bias-corrected estimates and standard errors for the aggregate efficiencies.

\subsection{Analysis of the determinants of banking efficiency}

In the second stage, the inverse of the efficiency measures $\left(\hat{\delta}_{i}=1 / \hat{\rho}_{i}\right)$ estimated using program (2) are regressed on environmental factors ${ }^{3}$. That is, $z_{i}$ is the vector of environmental variables of the $i$-th DMU and $\beta$ is a vector of parameters to be estimated associated with each environmental variable, as shown in equation (5):

$$
\hat{\delta}_{i}=z_{i} \beta+\varepsilon_{i} \geq 1
$$

However, the dependent variable $\hat{\delta}_{i}$ in (5) is an estimate of the unobserved true efficiency $\delta_{i}$, i.e., $\delta_{i}=\hat{\delta}_{i}=\left(\hat{\rho}\left(x_{i}, y_{i} \mid \hat{T}\right)\right)^{-1}$. Thus, all $\hat{\delta}_{i}$ 's are serially correlated in a complicated, unknown way; moreover, $\varepsilon_{i}$ is also correlated with $z_{i}$. To overcome this problem as well as improve on inference, we utilize the single bootstrap procedure (Algorithm 1) proposed by Simar and

\footnotetext{
${ }^{3}$ In the second stage, we use the inverse of the efficiency scores as this will give us efficiency measures which are bounded only at 1 and it is the only boundary to take into account in the truncated regression and, therefore, in the subsequent bootstrapping procedure, unlike the original input-oriented measures where, in the truncated regression, we need to consider 2 boundaries (at 0 and 1), which considerably complicates the likelihood function.
} 
Wilson (2007) where, in the bootstrap analysis, the efficiency scores are regressed on the environmental factors, as in the following equation ${ }^{4}$ :

$$
\delta_{i}=\psi\left(z_{i}, \beta\right)+\varepsilon_{i} \geq 1
$$

In equation (6), $\delta_{i}$ is the inverse of the efficiency measure $\rho_{i}$ of the $i$-th $\operatorname{DMU}\left(\hat{\rho}_{i}\right)$, calculated using program (2), and is considered as an estimate for $\left(\rho_{i}\right) ; \psi$ is a smooth continuous function; $\beta$ is a vector of parameters; and $\varepsilon_{i}$ is a truncated random variable $N\left(0, \sigma_{i}^{2}\right)$, truncated at $1-\psi\left(z_{i}, \beta\right)$.

In the bootstrap procedure, the efficiency measures $\hat{\delta}_{i}$ are used in the truncated regressions to obtain the bootstrap of the coefficients of the environmental variables affecting the performance of the banks and the variance of the regression. Thus, the bootstrap provides a set of bootstrapped parameters of the influencing factors which allows us to estimate their probabilities and confidence intervals. The following steps are performed in the second bootstrap procedure of Algorithm 1:

1. Estimate the truncated regression of $\hat{\delta}_{i}$ on $z_{i}$ in (6) for $m=n$ observations using the method of maximum likelihood estimation to obtain estimates for $\hat{\beta}$ and $\hat{\sigma}_{\varepsilon}$.

2. Compute a set of $L$ bootstrap estimates (we set $L$ to equal 1000 replications) for $\beta$ and $\sigma_{\varepsilon}$, $A=\left\{\left(\hat{\beta}^{*}, \hat{\sigma}_{\varepsilon}^{*}\right)_{b}\right\}_{b=1}^{L}$, in the following way: for each $i=1, \ldots, m$, draw $\varepsilon_{i}$ from the normal distribution $N\left(0, \hat{\sigma}_{\varepsilon}^{2}\right)$ with the left truncation of the distribution at $\left(1-z_{i} \hat{\beta}\right)$ and estimate $\delta_{i}^{*}=z_{i} \hat{\beta}+\varepsilon_{i}$; then estimate the truncated regression of $\delta_{i}^{*}$ on $z_{i}$ using maximum likelihood methods to obtain the parameter estimates $\left(\hat{\beta}^{*}, \hat{\sigma}_{\varepsilon}^{*}\right)$. . Once the set of $L$ bootstrap parameter estimates for $\beta$ and $\sigma_{\varepsilon}$ have been obtained, the percentile bootstrap confidence intervals can then be constructed. In addition, it becomes possible to test hypotheses, for example, to

\footnotetext{
${ }^{4}$ Although the Algorithm 2 of Simar and Wilson (2007) takes into account the bias of the efficiency score, in this study the Algorithm 1 is utilised. This is due to the better coverage of estimated confidence intervals performed by latter Algorithm.
} 
determine whether the $p$-value for a particular estimate where $\hat{\beta}<0$ is the relative frequency of the non-negative $\hat{\beta}^{*}$ bootstrap estimates.

This statistical procedure allows us to test the impact of environmental variables on banking inefficiency. Hence, in our regression stage of the modelling, we begin with a large set of macroeconomic factors which has the potential to influence the performance of banks, including individual components of GDP, such as private consumption expenditure, government expenditure, gross fixed capital formation, and net export of goods and services. In addition, we consider the inclusion of variables such as unemployment, expenditure on housing, the current account balance and the discount rate. Finally, to capture the effect of the scale efficiency of banks, in the regression specification we include a proxy for the size of the banks. In other words, we test the interaction of macroeconomic factors with size. We utilise Matlab software in all estimations, except in step 1 of Algorithm 1 where Stata 9 is utilised to obtain initial estimates of $\hat{\beta}$ and $\hat{\sigma}$ by use of a general-to-specific methodology ensuring a consistent step-down procedure to obtain the model specification with the best fit.

\subsection{Data description}

In this study we present comparative results from the two main methodologies utilised in the literature to model bank efficiency, the Intermediation and the Production approaches. In modelling the Intermediation approach we specify 4 outputs and 4 inputs (see Sealey and Lindley (1977)). The first output is 'total loans' (total customer loans + total other lending), the second output is 'other earning assets', the third output is 'net commission, fee and trading income', and the final output is 'other income'. The third and fourth outputs are included in the analysis to reflect the fact that banks around the world have been diversifying, at the margin, away from traditional financial intermediation (margin) business and into "off-balance-sheet" and fee income business. Hence, it would be inappropriate to focus exclusively on earning assets as this would fail to capture all the business operations of modern banks. The inclusion of 'other income' is therefore intended to proxy the non-traditional business activities of Hong Kong banks. 
The inputs estimated in the Intermediation approach are: 'total deposits' (total deposits + total money market funding + total other funding); 'total operating expenses' (personnel expenses + other administrative expenses + other operating expenses); 'total fixed assets'; and 'total provisions' (loan loss provisions + other provisions). Ideally, the labour input would be proxied either by number of employees or by personnel expenses. However, details on employment numbers are not available for all banks in the sample, while operating expenses data is not available on a disaggregated basis. Hence a 'total operating expense' variable was utilised. The summary statistics and distribution of banks are given in Table $1 .{ }^{5}$

\section{INSERT TABLE 1}

With respect to the last-mentioned input variable (i.e. provisions), it has long been argued in the literature that the incorporation of risk/loan quality is vitally important in studies of banking efficiency. Akhigbe and McNulty (2003), for example, utilising a profit function approach, include equity capital "to control, in a very rough fashion, for the potential increased cost of funds due to financial risk" (page. 312). Altunbas et al. (2000) and Drake and Hall (2003) also find that failure to adequately account for risk can have a significant impact on relative efficiency scores. In contrast to Akhigbe and McNulty (2003), however, Laevan and Majnoni (2003) argue that risk should be incorporated into efficiency studies via the inclusion of loan loss provisions. That is, "following the general consensus among risk agent analysts and practitioners, economic capital should be tailored to cope with unexpected losses, and loan loss reserves should instead buffer the expected component of the loss distribution. Consistent with this interpretation, loan loss provisions required to build up loan loss reserves should be considered and treated as a cost; a cost that will be faced with certainty over time but that is uncertain as to when it will materialise" (page 181). Hence, we also incorporate provisions as an input/cost in the DEA relative efficiency analysis of Hong Kong banks.

Finally, in the case of the Production approach, we have five outputs and three inputs. The outputs are: 'total customer loans' (customer loans + other lending); 'net commission, fee and trading income'; 'total deposits'; 'other earning assets'; and 'other operating

\footnotetext{
${ }^{5}$ The input and output data were obtained from the Bank-scope resource package by Bureau Van Dijik (BVD).
} 
income'. Ideally, a more appropriate measure of deposits to be used in the Production approach would be the number of deposit accounts. However, the required data for this specification was not available across the bank sample. The three inputs are: 'total other non-interest expenses' (personnel expenses + other administrative expenses); 'other operating expenses'; and 'total provisions' (loan loss provisions and other provisions). In the next Section we present our results.

\section{Results}

\subsection{First stage: SBM efficiency estimates}

Tables 2 and 3 provide a summary of the aggregate input-oriented, modified, slacks-based, bias-corrected efficiency scores obtained under the Intermediation and Production approaches to describing the banking production process. Although both approaches report similar trends in efficiency evolution, see Figures 1 and 2, the Intermediation approach generally produces higher results than the Production methodology. In particular, results suggest that in year 2001 the efficiencies of all the banking groups decreased dramatically. The later period of the analysed time span, the gradual improvement of the banking efficiency is observed. This is in line with the findings of Drake et al. (2008) who, in their case study of the Japanese banking industry, found Intermediation scores of 0.714 and 0.334 and Production scores of 0.334 and 0.286 in 2002 and 2001 respectively.

\section{INSERT FIGURES 1 AND 2}

Interestingly, in 2000, Hong Kong banks (taken as a group) exhibit high levels of Intermediation and Production efficiency ( $88 \%$ and 67\% respectively). However, in 2001, according to both approaches, the banks experienced a sharp decline in their efficiency levels (to $56 \%$ and $45 \%$ respectively). This may be attributed to two possible causes: firstly, the removal of interest rate controls in 2001 (see Section 2), and secondly, the possible impact of the fallout from the $9 / 11$ terrorist attacks in the US on an already fragile economy and thus on the banking industry of Hong Kong. Although the overall efficiency level remained 
moderately low in 2002 (at 62\% and 52\% respectively) commercial banks did, however, begin to show an improvement in their efficiencies. This improvement was particularly marked under the Production approach where efficiency increased from $42 \%$ to $66 \%$. After 2002, most banks recorded a steady improvement in efficiency, despite the SARS epidemic of 2003 (this is consistent with the industry's profits performance for 2003 reported in HKMA (2004)), although the investment bank grouping's efficiency dipped quite markedly in 2006.

Further, it is illuminating to note that, with respect to Hong Kong banks, Kwan (2006) found that the mean level of X-inefficiency for all banks over the sample was around 0.32 , and that inefficiency levels generally declined over the sample period (from 0.41 in 1992:Q1 to 0.29 in 1999:Q4). Kwan (2006) attributes the latter to the impact of technological innovation. However, in Drake et al. (2006), who utilised the SBM approach, the Hong Kong (overall) banking sectors' mean efficiency scores declined from 1995 (0.604) to 1999 (0.458), increased in 2000 (0.543) and then subsequently declined in 2001 (0.488). The latter pattern matches that established in our present study for the overlapping years (i.e. 2000/2001). ${ }^{6}$

\section{INSERT TABLES 2 AND 3}

Another, interesting finding is that commercial banks were also found to be more efficient than other types of banking firms under both approaches over most of the considered time period. Bank Holdings and Holding Companies (BHHC) are somewhat less efficient than commercial banks. Regarding the performance of Investment Banks, the results suggest that this group of banking firms is the most inefficient, with aggregate efficiency varying between a low of $36 \%$ in 2002 and a high of $68 \%$ in 2000 under the Intermediation approach, and 24\% in 2002 and $62 \%$ in 2000 under the Production approach.

Table 4 reports the results of the tests for equality of efficiency distributions estimated under the alternative approaches using an adapted version of Li (1996), the tests being modified to a DEA context in accordance with Simar and Zelenyuk (2006). As can be

\footnotetext{
${ }^{6}$ Note that, although in Drake et al. (2006) the results were based on Tone's (2001) original SBM specification and not on the Sharp et al. (2006) program used in this study, a general picture concerning trends can still be interpreted.
} 
seen, the efficiency scores estimated by the Production and Intermediation approaches are from different populations (i.e., have statistically different distributions), for all three groups of banks and the overall banking industry studied. This suggests that the SBM efficiency scores and the efficiency scores obtained utilising the traditional DEA technique (TortosaAusina, 2002) are alike in that they are sensitive to the choice of inputs and outputs adopted.

\section{INSERT TABLE 4 INSERT FIGURE 3}

The visualisation of the estimated density for all groups of banks using univariate kernels further supports this finding (Figure 3). The distribution of Production SBM efficiency scores (the dashed line) in all four diagrams is less steep than that of the Intermediation SBM efficiency scores (the solid line) in all but one case thereby indicating that more banks are concentrated around the mode of the Production approach. The pursuit of service-oriented objectives rather than financial intermediation activities may be the driving force behind this finding. However, the mode of the Intermediation efficiency scores' distribution is more to the left than of the Production efficiencies, implying that banks are more efficient in their role as financial intermediaries.

\section{INSERT FIGURE 4}

The bivariate kernel analysis presented in Figure 4 further suggests that, although the absolute value of the efficiency level is sensitive to the choice of the input and output specification adopted, in general, Hong Kong banks tend not to change their efficiency positions relative to that of the industry's average. This is due to the fact that the probability mass of the normalized efficiency scores relative to the geometric mean efficiency weighted by the size of the banks (proxied by the volume of deposits) is somewhat concentrated along the positive diagonal line.

\subsection{Analysis of the determinants of bank efficiency}


Tables 5 and 6 present results of the truncated regression analysis for the Intermediation and Production approaches respectively. The following macroeconomic variables were used in the specification of the truncated regression and gave the model with the best fit: LPRIVCONS - log of private consumption; LEXPORT - log of net exports (sum of the net export of services and the net export of goods); and LRENT - log of the rent for private flats on Hong Kong Island (as a proxy for housing expenditure). To capture the effects of time and bank specific characteristics, we further included a time trend (TIME) variable along with group dummies. Additionally, to capture the effects of scale we included the SIZE variable (log of total deposits) and the square of SIZE (SIZE^2). Finally, we included the interaction variable of the LEXPORT and SIZE (LEXPORT_SIZE) to capture the effect of the exportability of financial services of Hong Kong banks depending on the size of banking firm. According to the Information Services Department of the Hong Kong Special Administrative Region Government, in 2006, the share of exports of the financial services industry was $12 \%$ of the total value of the export of services. Therefore, it is particularly appealing to examine the influence of this variable on the efficiency of Hong Kong banking firms.

\section{INSERT TABLES 5 AND 6}

It is interesting to note that, although the significance of the variables is different for the inverse of the SBM efficiency scores under both Production and Intermediation approaches, the signs of the explanatory variables are the same. In both models, the indicators of size are found to be significant at the $1 \%$ level of significance with a positive coefficient for SIZE and a negative one for $\mathrm{SIZE}^{\wedge}$. This implies that in the Hong Kong banking industry, smaller banks are more efficient than their larger counterparts. However, larger banks are more likely to enjoy gains from scale economies. This is thus empirical evidence for the U-shaped scale economies implied by the theoretical literature. Moreover, similar signs of coefficients were found by Simar and Wilson (2007) in their empirical investigation of US commercial banks.

With respect to the macroeconomic determinants of banking (in)efficiency, the results suggest that the level of private consumption has a negative impact on banking inefficiency 
as expected. This implies that an increase in private consumption stimulates banking. Both LRENT and LEXPORT are found to be positively correlated with inefficiency and significant at the $1 \%$ level in the Production approach model and at the $10 \%$ level under the Intermediation framework. Interestingly, the coefficient for the interaction variable LEXPORT_SIZE is negative and significant in the Intermediation approach at the $10 \%$ level and with respect to the Production methodology, at the $1 \%$ level. This suggests that larger banks show a greater exportability of financial services. It can also be interpreted as larger banks having more opportunities to engage in exporting activities, thereby enhancing their efficiency.

Intriguingly, the results also show that the coefficient for the commercial banks' dummy is negative and significant in both models, whereas the coefficient of IB is negative and significant only in the Intermediation model. ${ }^{7}$ This implies that commercial banks are successful under both intermediation and service-producing objectives, whereas investment banks are only successful under the former..

\section{Conclusions}

The analysis presented in this paper shows that, under both the Intermediation and Production approaches, Hong Kong banks suffered a substantial decline in efficiency in the year 2001. This was probably due to deposit rate deregulation and the adverse consequences of the 9/11 terrorist attacks in the US. Utilising a relatively-new technique (Sharp et al. (2006)) to purge the Slacks-Based Methodology scores of any random error, we also find that the efficiency of banks was adversely affected in 2001. Adoption of the latter model is necessary because exogenous events can lead to 'bad luck' and hence interfere with the managerial operations of banks. Indeed, in the analysis of subsequent years, it was found that the same exogenous events which happened economy-wide could have a negative or positive effect on the efficiency results dependent on the bank sector considered. For example, under the Intermediation approach, commercial banks experienced negative bias

\footnotetext{
${ }^{7}$ The dummy for Bank Holdings and Holding Companies was dropped from the model due to collinearity problems.
} 
and investment banks positive bias during 2004-2006 (see Table 2). Finally, with respect to the bias-corrected efficiency scores, commercial banks were consistently closer to the best practice frontier than the other sectors of the industry (see Figures 1 and 2), starting at 0.937 (2000) and ending at 0.972 (2006) under the Intermediation approach.

Having obtained the bias-corrected efficiency scores, we proceeded to analyse the effects of macroeconomic factors on bank efficiency. Utilising a 'general-to-specific' stepdown procedure we found that all but the time trend (the other variables being private consumption, net exports and rent (all in logarithmic form)), had a significant effect on bank efficiency scores over the sample period, under both the Intermediation and Production approaches. It was interesting to find that the smaller banks were more efficient than the larger banks, but the latter were also able to enjoy economies of scale. This latter size factor was linked to the exportability of financial services, whereby the larger banks enjoyed a positive effect on bank efficiency given their ability to export services.

Finally, it is worth re-iterating that we found that the commercial banks enjoyed relative efficiency improvements over the sample period due to their ability to combine both intermediary and service-producing business activities. A possible policy conclusion from these results is that the financial system within Hong Kong could be further deregulated for non-commercial banks, hence allowing a possible increase in stability of the financial markets if a future Asian Financial Crisis, or any other 'bad luck' scenario in the World economy, happened. Thus, deregulation could allow for further diversification for, as we have seen, the banks which are able to diversify their assets most, appear to be the most insulated against external shocks with respect to their efficiency.

\section{Acknowledgments}

The authors would like to thank L. Simar, A. Afonso, V. Zelenyuk, T. Weyman-Jones and G. Ravishankar for helpful suggestions. 


\section{References}

Akhigbe, A. and McNulty, J.E. (2003), "The Profit Efficiency of Small US Commercial Banks," Journal of Banking and Finance, 27, 307-325.

Altunbas, Y., Liu, M-H., Molyneux, P. and Seth, R. (2000), "Efficiency and Risk in Japanese Banking," Journal of Banking and Finance, 24, 1605-1628.

Banker, R.D., Charnes, A. and Cooper, W.W. (1984), "Some Models for the Estimation of Technical and Scale Inefficiencies in Data Envelopment Analysis," Management Science, 30, 1078-1092.

Charnes, A., Cooper, W. and Rhodes, E. (1978), "Measuring the Efficiency of DecisionMaking Units," European Journal of Operational Research, 2, 429 - 444.

Drake, L. and Hall, M. J. B. (2003), "Efficiency in Japanese Banking: An Empirical Analysis," Journal of Banking and Finance, 27, 891-917.

Drake, L., Hall, M.J.B. and Simper, R. (2006), "The Impact of Macroeconomic and Regulatory Factors on Bank Efficiency: A Non-Parametric Analysis of Hong Kong's Banking System,” Journal of Banking and Finance, 30, 1443-1446.

Drake, L., Hall, M.J.B. and Simper, R. (2008), "Bank Modeling Methodologies: A Comparative Non-Parametric Analysis of Efficiency in the Japanese Banking Sector," Journal of International Financial Markets, Institutions and Money, 18, forthcoming.

Färe, R. and Zelenyuk, V. (2003), "On Aggregate Farrell Efficiencies," European Journal of Operations Research, 146:3, 615-621.

Färe, R., Grosskopf, S. and Lovell, C.A.K. (1985), The Measurement of Efficiency of Production. Kluwer- Nijhoff Publishing, Boston.

Farrell, M.J. (1957), "The Measurement of Productive Efficiency," Journal of the Royal Statistical Society, Ser. A, 120, 253-281.

Fried, H.O., Schmidt, S.S. and Yaisawarng, S. (1999), "Incorporating the Operating Environment into a Nonparametric Measure of Technical Efficiency," Journal of Productivity Analysis, 12, 249-267.

Goldstein, M. (1998), The Asian Financial Crisis: Causes, Cures and Systemic Implications, Institute for International Economics, Washington D.C., June. 
Hall, M.J.B. (1985), “The Reform of Banking Supervision in Hong Kong," Hong Kong Economic Papers, No.16, pp.74-96, Hong Kong, August.

HKMA (2002), Annual Report, 2002, Hong Kong.

HKMA (2004), 'Developments in the Banking Sector', Quarterly Bulletin, March, 81-89.

Hunter, W.C., Kaufman, G.G. and Krueger, T.H. (eds.) (1999), The Asian Financial Crisis: Origins, Implications and Solutions, Kluwer Academic Publishers

Jao, Y.C. (2001), The Asian Financial Crisis and the Ordeal of Hong Kong, Quorum Books, Greenwood Publishing.

Jao, Y.C. (2003), 'Financial Reform in Hong Kong,' Chapter 6 in Hall, M.J.B. (ed.), The International Handbook on Financial Reform, Edward Elgar Publishing, Cheltenham.

Krishnasamy, G., Ridzwa, A. H. and Perumal, V. (2003), "Malaysian Post Merger Banks' Productivity: Application of Malmquist Productivity Index," Managerial Finance, 30, 63-74.

Kwan, S. (2002), “The X-Efficiency of Commercial Banks in Hong Kong," Hong Kong Institute for Monetary Research, Working Paper No. 12/2002.

Laeven, L. and Majnoni, G. (2003), "Loan Loss Provisioning and Economic Slowdowns:

Too Much, Too Late?” Journal of Financial Intermediation, 12, 178-197.

Li, Q. (1996), "Nonparametric Testing of Closeness between Two Unknown Distributions”, Econometric Reviews, 15, 261-274.

Lozano-Vivas, A., Pastor, J.A. and Pastor, J.M. (2002), "An Efficiency Comparison of European Banking Systems Operating under Different Environmental Conditions," Journal of Productivity Analysis, 18, 59-77.

Pastor, J. T. (1996), "Translation Invariance in Data Envelopment Analysis: A Generalization," Annals of Operations Research, 66, 93-102.

Sealey, C. and Lindley, J.T. (1977), "Inputs, Outputs and a Theory of Production and Cost at Depository Financial Institutions," Journal of Finance, 32, 1251-1266.

Sharp, J.A., Meng, W. and Liu, W. (2006), “A Modified Slacks-Based Measure Model for Data Envelopment Analysis with 'Natural' Negative Outputs and Inputs," Journal of the Operational Research Society, 58, 1672-1677. 
Sheather, S. J. and Jones, M.C. (1991), “A Reliable Data-Based Bandwidth Selection Method for Kernel Density Estimation,” Journal of the Royal Statistical Society, Ser. B, 53(3), 683-690.

Shen, C-H. (2005), "Cost Efficiency and Banking Performance in a Partial Universal Banking System: Application of the Panel Smooth Threshold Model," Applied Economics, 37, 993-1009.

Silva-Portela, M.C.A, Thanassoulis, E. and Simpson, G. (2004), "Negative Data in DEA: A Directional Distance Approach Applied to Bank Branches," Journal of the Operational Research Society, 55, 1111-1121.

Silverman, B. W. (1986), Density Estimation for Statistics and Data Analysis. Chapman and Hall, London, UK.

Simar, L. and Wilson P.W. (2007), "Estimation and Inference in Two-Stage Semi-Parametric Models of Production Processes," Journal of Econometrics, 136, 31-64.

Simar, L. and Zelenyuk, V. (2006), "On Testing Equality of Two Distribution Functions of Efficiency Scores Estimated from DEA,” Econometric Reviews, 25, 497-522.

Simar, L. and Zelenyuk, V.(2007), "Statistical Inference for Aggregates of Farrell-Type Efficiencies," Journal of Applied Econometrics, forthcoming.

Tone, K. (2001), "A Slack - Based Measure of Efficiency in Data Envelopment Analysis," European Journal of Operational Research, 130, 498 - 509.

Tortosa-Ausina, E. (2002), "Bank Cost Efficiency and Output Specification," Journal of Productivity Analysis, 18, 199-222.

Wand, M. P. and Jones, M.C. (1994), "Multivariate Plug-in Bandwidth Selection," Computational Statistics 9, 97-116. 
Table 1.

Hong Kong Banks: Summary Statistics and Distribution of Analyzed Banks across the Banking Groups

\begin{tabular}{lllll}
\hline & mean & min & max & st. dev \\
\hline Total Operating Expenses & 1541876 & 1800 & 45167256 & 4659830 \\
Fixed Assets & 2769599 & 100 & 49216374 & 7331098 \\
Total Deposits and Funding & 122029945 & 1761 & 3249308598 & 358086443 \\
Total Loans & 61695841 & 338 & 1229425206 & 162984058 \\
Other Earning Assets & 67505775 & 0 & 1993631331 & 205726006 \\
Loan loss provisions & 318161 & -3104460 & 8593000 & 1092042 \\
Net com Income + Other & & & & \\
operating Income & 1174795 & -1865023 & 38054181 & 4019743 \\
& BHHC & $C B$ & $I B$ & Total \\
\hline 2000 & 4 & 23 & 29 & 56 \\
2001 & 5 & 22 & 25 & 52 \\
2002 & 6 & 23 & 20 & 49 \\
2003 & 6 & 22 & 18 & 46 \\
2004 & 6 & 21 & 18 & 45 \\
2005 & 4 & 20 & 16 & 40 \\
2006 & 5 & 18 & 8 & 31 \\
\hline
\end{tabular}

Notes. Figures for variables are expressed in $\mathrm{HK} \$$ millions and deflated using the Hong Kong GDP deflator. BHHC - Bank Holding \& Holding Company, CB - Commercial Bank, IB -Investment Bank/Securities House. 
Table 2.

Group-Wise Heterogeneous Sub-Sampling Bootstrap Aggregate Efficiencies

Under the Intermediation Approach

\begin{tabular}{|c|c|c|c|c|c|c|c|c|}
\hline & & 2000 & 2001 & 2002 & 2003 & 2004 & 2005 & 2006 \\
\hline $\mathrm{BHHC}-\mathrm{B}$ & k Holdings & d Hold & Compa & & & & & \\
\hline Original SE & M score & 0.827 & 0.659 & 0.714 & 0.747 & 0.874 & 0.743 & 0.905 \\
\hline & Bias-corr & & & & & & & \\
\hline Bootstrap & SBM eff. & 0.821 & 0.585 & 0.517 & 0.641 & 0.866 & 0.661 & 0.868 \\
\hline estimates & Stn.dev. & 0.092 & 0.115 & 0.094 & 0.069 & 0.103 & 0.049 & 0.109 \\
\hline & CI 5\% Up & 0.669 & 0.360 & 0.428 & 0.521 & 0.748 & 0.560 & 0.811 \\
\hline & CI $5 \%$ Lo & 0.976 & 0.793 & 0.767 & 0.773 & 1.115 & 0.749 & 1.204 \\
\hline $\mathrm{CB}-\mathrm{Comr}$ & ercial Banks & & & & & & & \\
\hline Original SE & M score & 0.893 & 0.712 & 0.756 & 0.873 & 0.922 & 0.931 & 0.935 \\
\hline & Bias-corr & & & & & & & \\
\hline Bootstrap & SBM eff. & 0.937 & 0.560 & 0.699 & 0.862 & 0.926 & 0.967 & 0.972 \\
\hline estimates & Stn.dev. & 0.068 & 0.065 & 0.116 & 0.073 & 0.087 & 0.061 & 0.074 \\
\hline & CI 5\% Up & 0.822 & 0.455 & 0.538 & 0.768 & 0.880 & 0.884 & 0.889 \\
\hline & CI 5\% Lo & 1.096 & 0.705 & 0.944 & 1.041 & 1.219 & 1.107 & 1.131 \\
\hline IB - Invest & ent Banks & & & & & & & \\
\hline Original SE & M score & 0.745 & 0.681 & 0.623 & 0.662 & 0.792 & 0.687 & 0.669 \\
\hline & Bias-corr & & & & & & & \\
\hline Bootstrap & SBM eff. & 0.684 & 0.499 & 0.362 & 0.515 & 0.668 & 0.551 & 0.458 \\
\hline estimates & Stn.dev. & 0.075 & 0.042 & 0.055 & 0.047 & 0.036 & 0.048 & 0.062 \\
\hline & CI 5\% Up & 0.573 & 0.426 & 0.285 & 0.426 & 0.612 & 0.469 & 0.346 \\
\hline & CI 5\% Lo & 0.863 & 0.588 & 0.484 & 0.613 & 0.749 & 0.660 & 0.588 \\
\hline All Banks & & & & & & & & \\
\hline Original SE & M score & 0.860 & 0.699 & 0.733 & 0.827 & 0.898 & 0.891 & 0.911 \\
\hline Bootstrap & Bias-corr & & & & & & & \\
\hline estimates & SBM eff. & 0.881 & 0.560 & 0.618 & 0.788 & 0.938 & 0.905 & 0.919 \\
\hline & Stn.dev. & 0.059 & 0.066 & 0.088 & 0.058 & 0.071 & 0.050 & 0.068 \\
\hline & CI 5\% Up & 0.776 & 0.453 & 0.499 & 0.704 & 0.833 & 0.829 & 0.843 \\
\hline & CI 5\% Lo & 1.003 & 0.707 & 0.828 & 0.917 & 1.105 & 1.019 & 1.091 \\
\hline
\end{tabular}

Notes: We use 1000 group-wise heterogeneous bootstrap replications, Gaussian density, and the Silverman (1986) reflection method; and the bandwidth is obtained using the Sheather and Jones (1991) solve-the-equation plug-inapproach. CI 5\% Up and CI 5\% Lo indicate 5\% Confidence Intervals at the Upper and Lower levels respectively. 
Table 3.

Group-Wise Heterogeneous Sub-Sampling Bootstrap Aggregate Efficiencies

Under the Production Approach

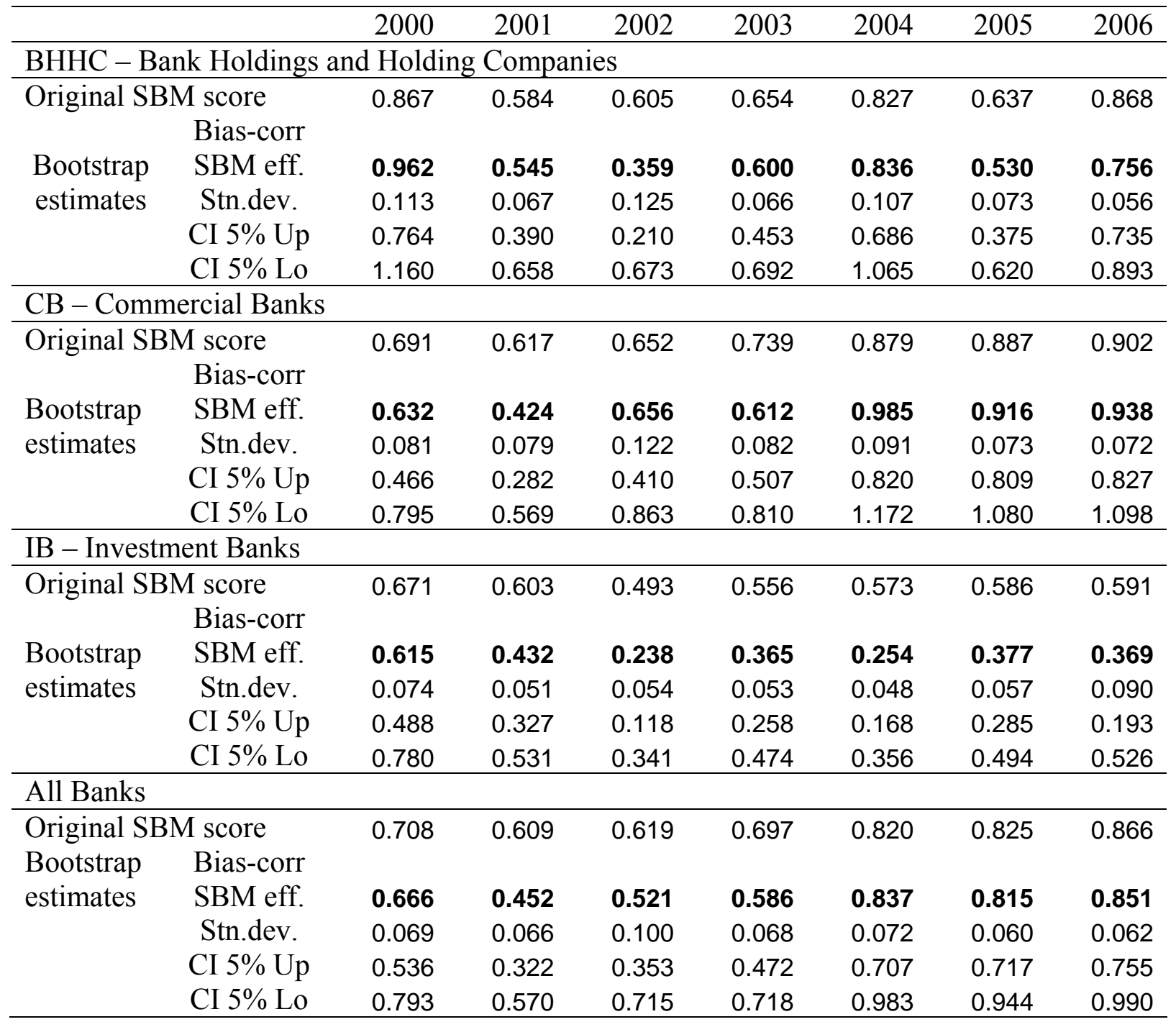

Notes: We use 1000 group-wise heterogeneous bootstrap replications, Gaussian density, and the Silverman (1986) reflection method; and the bandwidth is obtained using the Sheather and Jones (1991) solve-the-equation plug-inapproach. CI 5\% Up and CI 5\% Lo indicate 5\% Confidence Intervals at the Upper and Lower levels respectively. 
Table 4.

Simar-Zelenyuk-Adapted Li Test for Equality of Efficiency Distributions

\begin{tabular}{lll}
\hline Null Hypothesis & Test Statistics & Bootstrap p-value \\
\hline$f\left(\mathrm{Eff}_{\text {Prod }}\right)=f\left(\mathrm{Eff}_{\text {Interm }}\right)$ & 15.681 & $0.000^{* *}$ \\
$f\left(\mathrm{Eff}_{\operatorname{Prod} B H H C}\right)=f\left(\mathrm{Eff}_{\text {Interm } B H H C}\right)$ & 1.6015 & $0.0396^{*}$ \\
$f\left(\mathrm{Eff}_{\operatorname{Prod} C B}\right)=f\left(\mathrm{Eff}_{\text {Interm } C B}\right)$ & 5.4755 & $0.000^{* *}$ \\
$f\left(\mathrm{Eff}_{\operatorname{Prod} I B}\right)=f\left(\mathrm{Eff}_{\text {Interm } I B}\right)$ & 10.660 & $0.000^{* *}$ \\
\hline
\end{tabular}

Notes: (Interm) Intermediation Approach, (Prod) Production Approach. The number of bootstrap iterations is 5000. For these tests, we use the Gaussian density, and the bandwidth $h$ used in the tests is the minimum of the

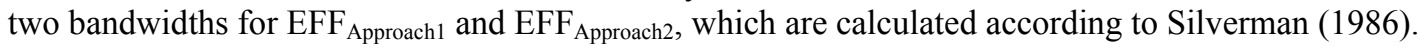

Statistical significance: * statistically significant at 5\% level; ** statistically significant at $1 \%$ level. 
Table 5.

Results of Truncated Regression Analysis Using Algorithm 1

(Intermediation Approach).

\begin{tabular}{|c|c|c|c|c|c|c|c|}
\hline & \multirow{2}{*}{$\begin{array}{l}\text { Est.Coeff. } \\
\text { (p-value) }\end{array}$} & \multicolumn{6}{|c|}{ Bounds of the Bootstrap Est. confidence intervals } \\
\hline & & $\begin{array}{l}\text { Lower } \\
5 \%\end{array}$ & $\begin{array}{l}\text { Upper } \\
5 \%\end{array}$ & $\begin{array}{l}\text { Lower } \\
1 \%\end{array}$ & $\begin{array}{l}\text { Upper } \\
1 \%\end{array}$ & $\begin{array}{l}\text { Lower } \\
10 \%\end{array}$ & $\begin{array}{l}\text { Upper } \\
10 \%\end{array}$ \\
\hline SIZE & $\begin{array}{c}1.6990^{* * *} \\
(0.000)\end{array}$ & 0.812 & 2.717 & 0.656 & 3.210 & 0.922 & 2.482 \\
\hline $\mathrm{SIZE}^{\wedge} 2$ & $\begin{array}{c}-0.0403 * * * \\
(0.000)\end{array}$ & -0.064 & -0.022 & -0.077 & -0.018 & -0.059 & -0.024 \\
\hline LPRIVCONS & $\begin{array}{c}-4.4699^{* *} \\
(0.012)\end{array}$ & -8.900 & -0.396 & -10.267 & 0.669 & -8.036 & -0.966 \\
\hline LEXPORT & $\begin{array}{l}1.3270^{*} \\
(0.073)\end{array}$ & -0.300 & 3.102 & -1.093 & 3.681 & -0.128 & 2.822 \\
\hline LRENT & $\begin{array}{c}3.0003^{*} \\
(0.059)\end{array}$ & -0.544 & 6.610 & -1.780 & 8.141 & -0.127 & 5.995 \\
\hline $\begin{array}{c}\text { LEXPORT* } \\
\text { SIZE } \\
\text { TIME }\end{array}$ & $\begin{array}{c}-0.0923^{*} \\
(0.052) \\
0.0697\end{array}$ & -0.205 & 0.017 & -0.268 & 0.058 & -0.182 & 0.001 \\
\hline & $(0.220)$ & -0.115 & 0.255 & -0.166 & 0.309 & -0.082 & 0.220 \\
\hline $\mathrm{CB}$ & $\begin{array}{c}-0.4404^{* *} \\
(0.014)\end{array}$ & -0.781 & -0.058 & -0.896 & 0.107 & -0.724 & -0.128 \\
\hline IB & $\begin{array}{c}-0.4528^{* *} \\
(0.021)\end{array}$ & -0.855 & -0.009 & -0.935 & 0.151 & -0.800 & -0.083 \\
\hline$\hat{\sigma}_{\varepsilon}$ & $\begin{array}{c}0.6234 * * * \\
(0.000)\end{array}$ & 0.509 & 0.722 & 0.489 & 0.766 & 0.520 & 0.697 \\
\hline
\end{tabular}

Notes: The regressed variable is the inverse of the MSBM input efficiency score estimates. *,**,*** denote significance at the $10 \%, 5 \%$ and $1 \%$ levels respectively according to the frequency of the bootstrapped parameters with the same sign. 
Table 6.

Results of Truncated Regression Analysis Using Algorithm 1

(Production Approach).

\begin{tabular}{|c|c|c|c|c|c|c|c|}
\hline & \multirow{2}{*}{$\begin{array}{l}\text { Est.Coeff. } \\
\text { (p-value) }\end{array}$} & \multicolumn{6}{|c|}{ Bounds of the Bootstrap Est. confidence intervals } \\
\hline & & $\begin{array}{l}\text { Lower } \\
5 \%\end{array}$ & $\begin{array}{l}\text { Upper } \\
5 \%\end{array}$ & $\begin{array}{l}\text { Lower } \\
1 \%\end{array}$ & $\begin{array}{l}\text { Upper } \\
1 \%\end{array}$ & $\begin{array}{l}\text { Lower } \\
10 \%\end{array}$ & $\begin{array}{l}\text { Upper } \\
10 \%\end{array}$ \\
\hline SIZE & $\begin{array}{c}1.3523 * * * \\
(0.000)\end{array}$ & 0.947 & 1.787 & 0.822 & 1.916 & 1.004 & 1.719 \\
\hline $\mathrm{SIZE}^{\wedge} 2$ & $\begin{array}{c}-0.0226 * * * \\
(0.000)\end{array}$ & -0.031 & -0.014 & -0.036 & -0.011 & -0.030 & -0.016 \\
\hline LPRIVCONS & $\begin{array}{c}-3.8893 * * * \\
(0.000)\end{array}$ & -5.954 & -1.924 & -6.569 & -1.354 & -5.642 & -2.252 \\
\hline LEXPORT & $\begin{array}{c}1.7483 * * * \\
(0.000)\end{array}$ & 0.893 & 2.676 & 0.687 & 2.921 & 1.059 & 2.523 \\
\hline LRENT & $\begin{array}{c}2.2071 * * * \\
(0.005)\end{array}$ & 0.470 & 3.912 & -0.038 & 4.455 & 0.782 & 3.627 \\
\hline $\begin{array}{l}\text { LEXPORT* }^{*} \\
\text { SIZE }\end{array}$ & $\begin{array}{c}-0.1047 * * * \\
(0.000)\end{array}$ & -0.159 & -0.054 & -0.175 & -0.044 & -0.151 & -0.061 \\
\hline TIME & $\begin{array}{c}0.0334 \\
(0.231)\end{array}$ & -0.048 & 0.125 & -0.073 & 0.158 & -0.035 & 0.113 \\
\hline $\mathrm{CB}$ & $\begin{array}{c}-0.1391 * \\
(0.093)\end{array}$ & -0.338 & 0.079 & -0.379 & 0.155 & -0.290 & 0.044 \\
\hline IB & $\begin{array}{l}0.0146 \\
(0.437) \\
\end{array}$ & -0.215 & 0.251 & -0.287 & 0.318 & -0.184 & 0.206 \\
\hline$\hat{\sigma}_{\varepsilon}$ & $\begin{array}{c}0.4427 * * * \\
(0.000)\end{array}$ & 0.389 & 0.482 & 0.378 & 0.495 & 0.395 & 0.473 \\
\hline
\end{tabular}

Notes: The regressed variable is the inverse of the MSBM input efficiency score estimates. $*, * *, * * *$ denote significance at the $10 \%, 5 \%$ and $1 \%$ levels respectively according to the frequency of the bootstrapped parameters with the same sign. 
Figure 1

Dynamics of Aggregate Efficiency of Banking Groups (Intermediation Approach)

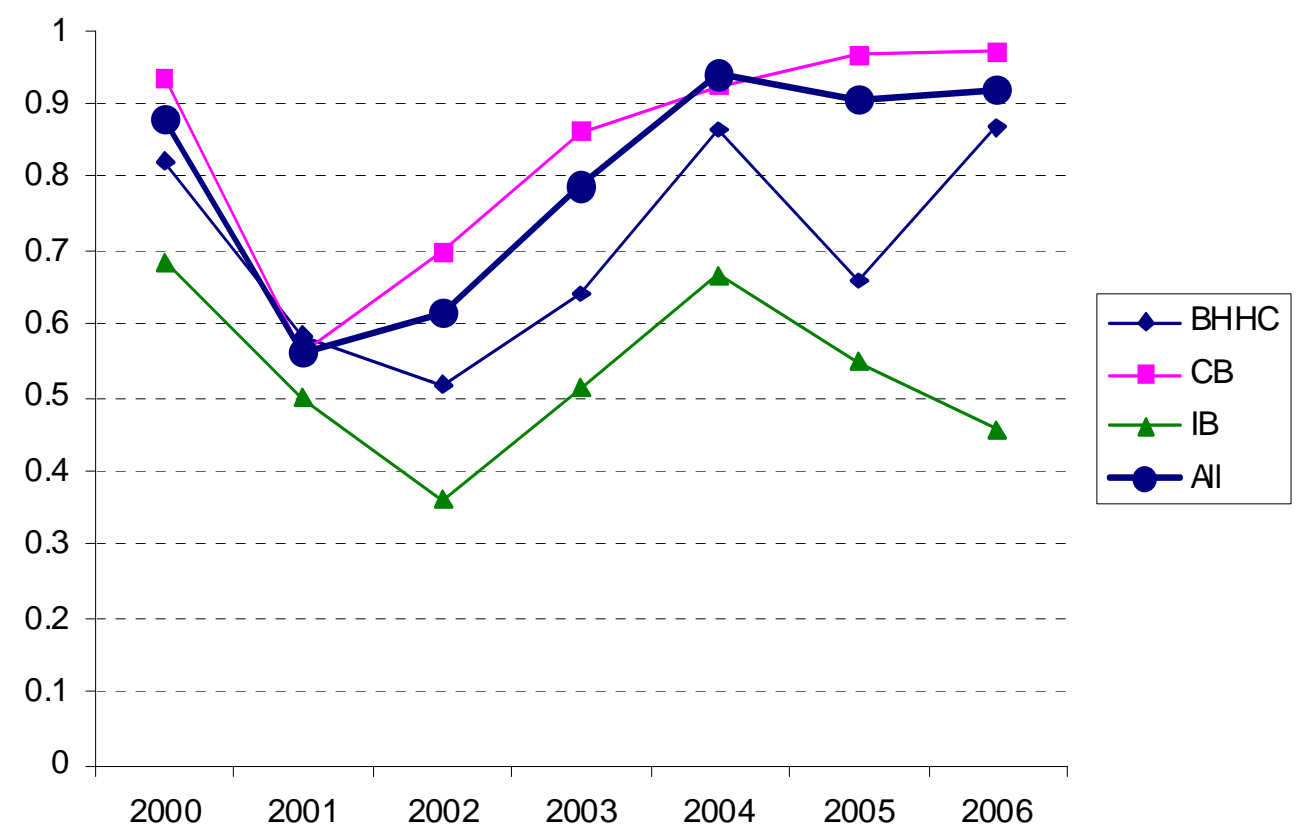

Figure 2

Dynamics of Aggregate Efficiency of Banking Groups (Production Approach)

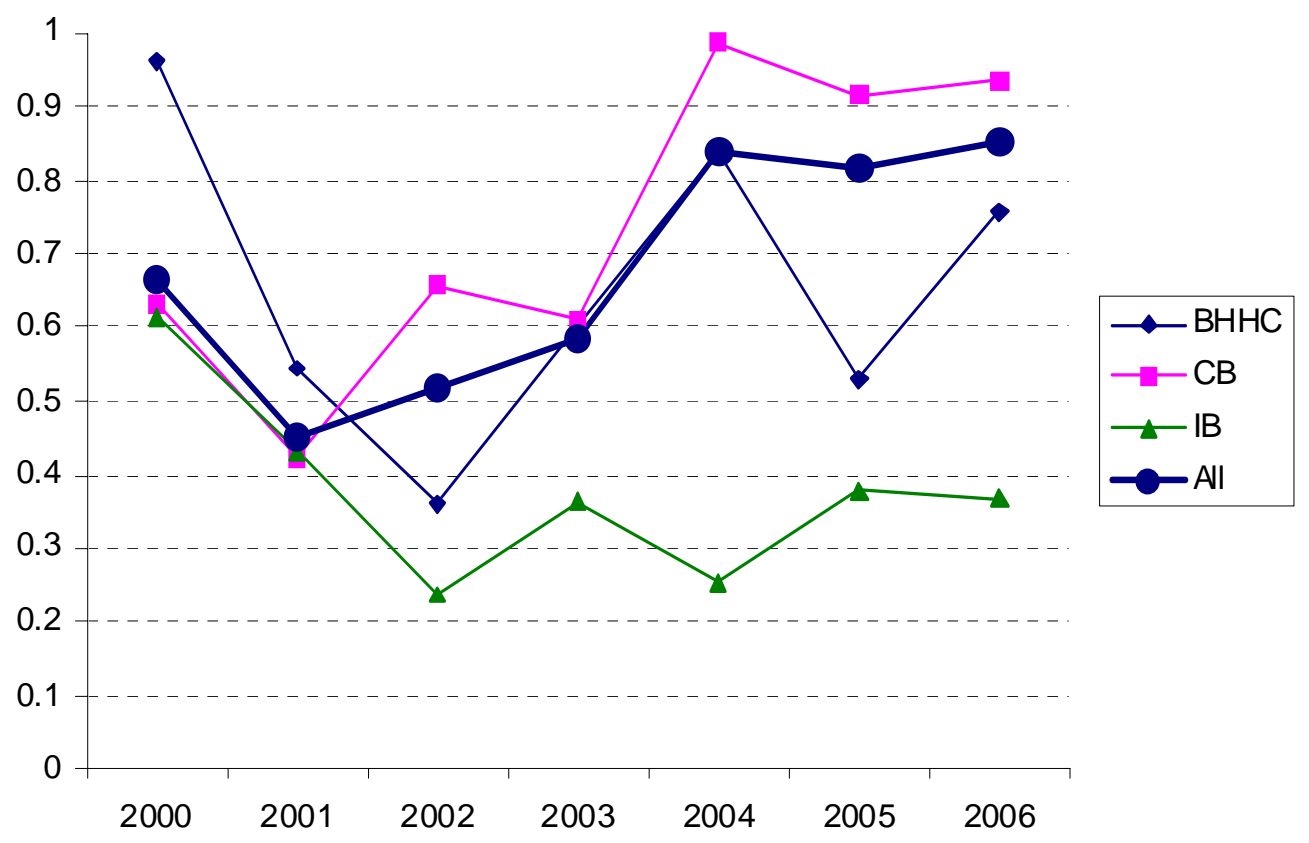


Figure 3.

Distribution of SBM Efficiency Scores by Type of Banking Firm Under the Two Alternative Approaches.
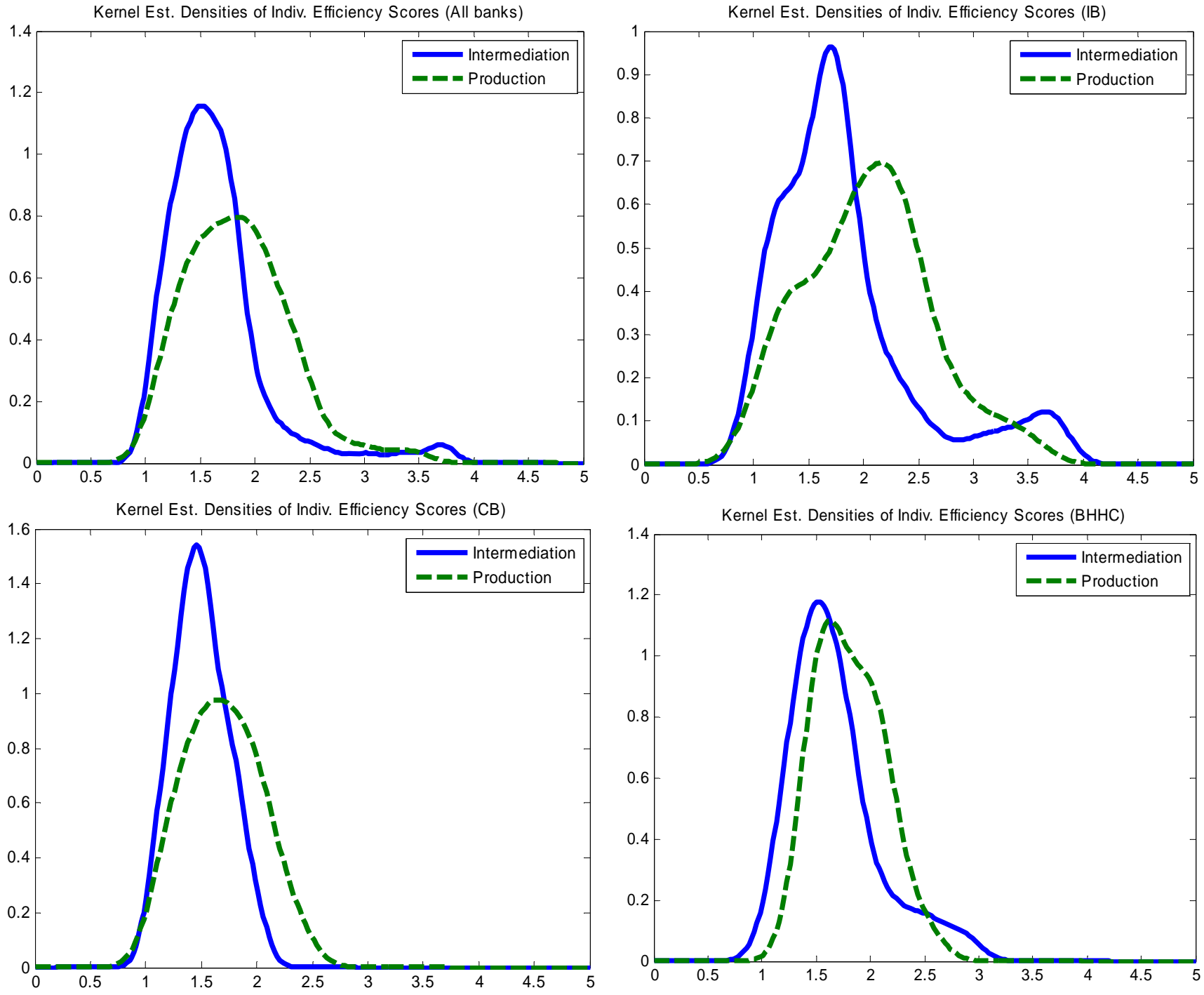

Note. Vertical axis refers to (estimated) probability density function of the distribution of efficiency scores and horizontal axis refers to efficiency scores (reflected). The univariate Gaussian kernel is used, and the bandwidth is obtained using the Sheather and Jones (1991) solvethe-equation plug-in approach. 


\section{Figure 4.}

Normalised slacks-based efficiency $\hat{\rho}_{i}$ 's: transition across alternative output definitions.
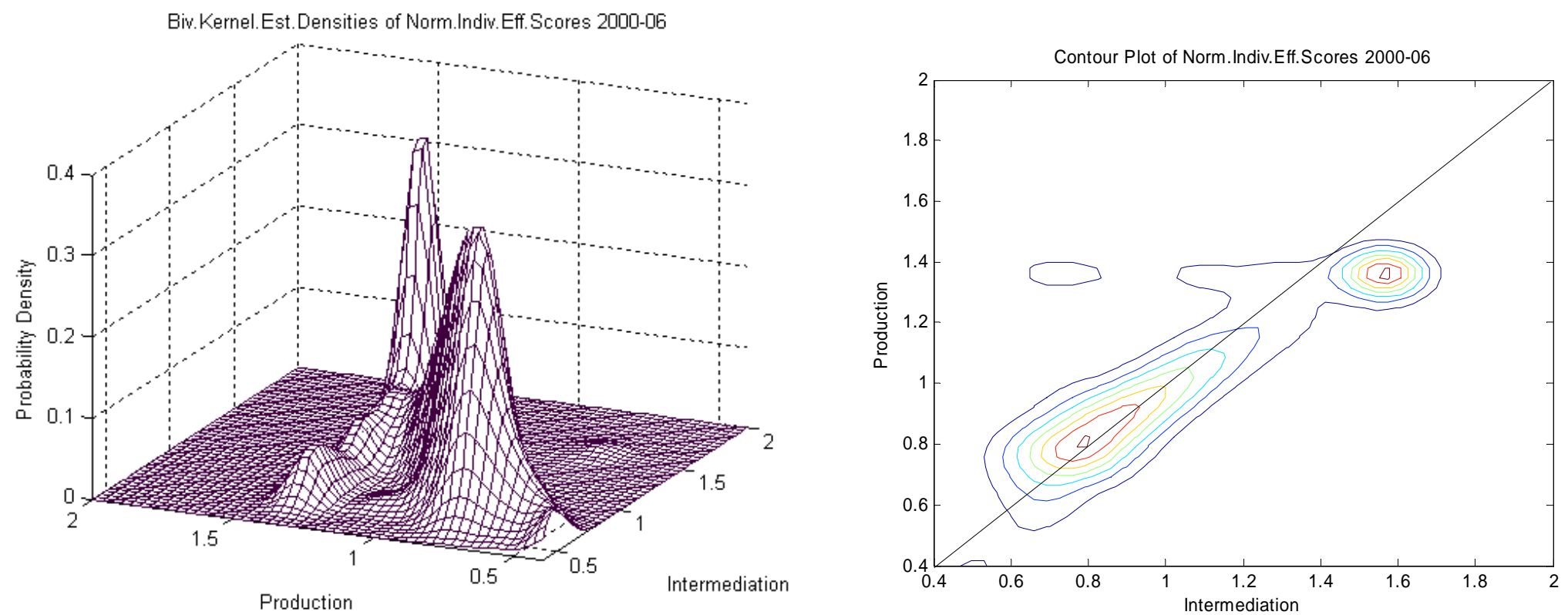

Note. The bivariate Gaussian kernel is used, and the bandwidths are calculated according to the solve-the-equation plug-in approach for the bivariate Gaussian kernel, based on Wand and Jones (1994). 